\title{
Influence of CYP4F2, ApoE, and CYP2A6 gene polymorphisms on the variability of Warfarin dosage requirements and susceptibility to cardiovascular disease in Jordan
}

\author{
Laith N. AL-Eitan ${ }^{1,2}$, Ayah Y. Almasri ${ }^{1}$, Adan H. Alnaamneh ${ }^{1}$, Hatem A. Aman², Nasr N. Alrabadi ${ }^{3}$, Rame \\ H Khasawneh4, Mansour A. Alghamdi 5,6 \\ 1. Department of Applied Biological Sciences, Jordan University of Science and Technology, Irbid 22110, Jordan. \\ 2. Department of Biotechnology and Genetic Engineering, Jordan University of Science and Technology, Irbid 22110, Jordan. \\ 3. Department of Pharmacology, Faculty of Medicine, Jordan University of Science and Technology, Irbid 22110, Jordan. \\ 4. Department of Hematopathology, King Hussein Medical Center (KHMC), Royal Medical Services (RMS), Amman 11118, Jordan \\ 5. Department of Anatomy, College of Medicine, King Khalid University, Abha 61421, Saudi Arabi. \\ 6. Genomics and Personalized Medicine Unit, College of Medicine, King Khalid University, Abha 61421, Saudi Arabia. \\ $\triangle$ Corresponding author: Laith N. AL-Eitan; Department of Biotechnology \& Genetic Engineering/Faculty of Science and Arts/Jordan University of Science \\ and Technology; P.O.Box 3030, Irbid 22110, Jordan; Tel.: +962-2-7201000 ext.: 23464; E-mail: lneitan@just.edu.jo. \\ (c) The author(s). This is an open access article distributed under the terms of the Creative Commons Attribution License (https://creativecommons.org/licenses/by/4.0/). \\ See http:/ /ivyspring.com/terms for full terms and conditions.
}

Received: 2020.08.05; Accepted: 2020.12.02; Published: 2021.01.01

\begin{abstract}
Cardiovascular diseases are among the leading causes of death worldwide. Many of those diseases require treatment with warfarin, an anticoagulant that has a large high inter and intra-variability in the required doses. The aim of this study is to find if there are any associations between rs 2108622 of CYP4F2, rs7412 and rs 405509 of $A p o E$, and rs1801272 of CYP2A6, and CVD and warfarin dose variability. The selected genes and their polymorphisms are involved in many GWAS associated with cardiovascular disease and variability in warfarin treatment. The study sample consisted of 212 Jordanian Cardiovascular patients and 213 healthy controls. DNA was extracted and the Mass ARRAY ${ }^{\mathrm{TM}}$ system was used to genotype four selected SNPs within three genes (CYP4F2, ApoE, and CYP2A6). Only one out of the four selected SNPs (ApoE rs7412 SNP) was found to be associated with the risk of cardiovascular disease. Also, this SNP showed significant differences in warfarin initial doses. CYP2A6 rs 1801272 SNP was found to be associated with warfarin sensitivity during the initiation phase of therapy and with warfarin responsiveness and INR measurement during the stabilization phase of therapy. This study improves the current understanding of the high inter and intra-variabilities in response to warfarin, including the variety of dosing requirements and the susceptibility to cardiovascular disease in the Jordanian Arab population. Further study on a larger sample and in different ethnic groups could help in improving our understanding of warfarin's pharmacogenetics and its application in personalized medicine.
\end{abstract}

Key words: Warfarin, cardiovascular disease, APOE, CYP4F2, and CYP2A6

\section{Introduction}

Heart disease is a term commonly referred to as cardiovascular disease (CVD), which defines several disorders that affect the heart and blood vessels, including Coronary heart disease (CHD), Myocardial Infarction (MI), deep vein thrombosis, pulmonary embolism, and rheumatic heart disease [1]. According to the World Health Organization (WHO), CVDs are the leading cause of death worldwide. In addition, more than three-quarters of CVD deaths occur in developing (low and middle-income) countries, such as Jordan [2]. Therefore, in order to reduce the burden of CVD in these countries, we must struggle to combine our knowledge about the risk factors of the disease, as well as our understanding of the effectiveness of successful therapeutic interventions. While a large number of risk factors for CVD have been identified in epidemiological studies, such as blood pressure, plasma lipid levels, diabetes, and 
smoking, familial studies and studies on twins have shown that about $40-50 \%$ of the susceptibility to CVD corresponds to the genetic factors [3]. Several genetic risk factors associated with CVD have been identified in several studies, including mutations in CYP4F2, ApoE, and CYP2A6 [4-7]. Genetic analysis and mutational genotyping could potentially improve patients' outcomes if treatment is initiated early. However, more exploration is required.

The CYP4F2 gene is a member of the CYP450 superfamily. It encodes an enzyme that plays a key role in the metabolism of endogenous and exogenous molecules such as vitamins $\mathrm{K}$ and $\mathrm{E}$ [8]. As well, this enzyme is responsible for the metabolism of 20-hydroxy-eicosan-arachidonic acid (20-HETE). In rat hypertensive models, the increase in 20-HETE can cause oxidative stress and endothelial cell damage, which in turn increases the incidence of ischemic stroke (IS) [9]. Recent studies in the Chinese population have shown that CYP4F2 is associated with an increased risk of IS [10]. On the other hand, the ApoE gene located on chromosome 19 encodes an enzyme that plays an important role in lipoprotein metabolism. It facilitates the binding of lipoproteins to LDL receptors. However, defects in ApoE protein can reduce the ability of lipoproteins to bind to receptors, leading to high levels of cholesterol in the blood [11]. Several studies have shown that ApoE polymorphisms are related to fluctuations in blood cholesterol. Therefore, they increase the risk of premature atherosclerosis and CVD, especially for coronary heart disease [12]. The human cytochrome P450 gene (CYP2A6) encodes an enzyme that is predominantly expressed in the liver and is responsible for the metabolism of several clinically relevant substrates $[13,14]$. However, the enzymatic activity of CYP2A6 and its metabolism varies greatly among individuals. The genetic variation of the CYP2A6 gene is considered an important predictor of its activity [15].

One of the most commonly used anticoagulants for the treatment and prevention of thromboembolic disorders is warfarin [16]. It consists of a mixture of $R$ and $\mathrm{S}$ isomers, with the $\mathrm{S}$ isoform having an activity two to five times greater than the $\mathrm{R}$ isoform. The cytochrome P450 2C9 enzyme (CYP2C9) is the main system responsible for the metabolism of the $\mathrm{S}$ isoform in the liver [16, 17]. Warfarin acts as an anticoagulant by binding to subunit 1 of vitamin $\mathrm{K}$ epoxide reductase (VKORC1), an enzyme required for the coagulation factors activation [18]. In order to keep warfarin therapy safe and accurate, prothrombin time should be maintained at a therapeutic range, characterized by the International Normalized Ratio (INR) [19].

Moreover, achieving therapeutic INR may take weeks and can increase the risk of adverse drug reactions in the early stages of therapy [20]. Thus, knowing how genetic and environmental factors influence the anticoagulant effect of warfarin will help in predicting the proper individualized/ personalized doses and leading to more accurate and safer treatment [21-23]. Polymorphisms in the genes encoding drug receptors, metabolic enzymes, and transporters may regulate the response to warfarin [24]. Similarly, a pharmacogenetics analysis revealed that genetic variations in the CYP2C9 and VKORC1 genes significantly affected the individual response to warfarin [25-27]. Until now, there is no specific way to determine the exact dose of warfarin to reduce the risk of bleeding. Therefore, it is valuable to increase our understanding of the candidate genes associated with the oral anticoagulation pathway [28]. The aim of the present study was to evaluate the genotypic associations between the selected SNPs in the CYP4F2, ApoE, and CYP2A6 genes and the variability of the warfarin dose in Jordanian cardiovascular patients. As well, those genetic variations were assessed for their association with the risk factors and the susceptibility to CVDs.

\section{Materials and Methods}

\section{Subjects}

This study was ethically approved by the Royal Medical Services of Amman and the Human Research Committees of the Jordan University of Science and Technology in Irbid. Patients with written consent from the Queen's Alia Heart Institute Anticoagulation Clinics in Amman (a referral heart center for the peripheral military centers in Jordan) were enrolled in this study. This study excluded patients who received CYP2C9 inducer or inhibitor medications, those who received concomitant medications that interact with, those who lost clinical data, patients known for alcohol consumption, and pregnant women. A total of 425 subjects participated in this study; non-cardiovascular health controls $(n=213)$ and cardiovascular patients $(n=212)$ over 18 years of age who had been receiving warfarin for at least 3 months.

\section{Data collection and follow-up time}

Blood samples were collected to determine the value of INR and to genotype selected SNPs. Demographic characteristics include (body mass index, age, and gender), indications for warfarin treatment, a weekly average of INR value, a weekly average of warfarin dose (dose required to obtain therapeutic INR), medical problems, and concomitant medications were recorded during the patient clinic visits. Warfarin dose and INR values were recorded in two phases, the first phase is the beginning of the 
treatment where the INR values are unstable and is called (initiation phase of the therapy), and the second phase is when the INR values are stable in the therapeutic range for at least three sequential clinic visits, this stage is called (stabilization phase of therapy).

\section{Outcome measure}

This study was divided into two main categories: a genetic association study (comparing the selected polymorphism between patients and control) and a pharmacogenetics study (examining the influence of the selected polymorphisms on warfarin treatment during the initiation and stabilization phases of therapy). The pharmacogenetics study addresses two main concepts. Warfarin sensitivity was the first concept: patients in this group were defined as either warfarin-resistant patients, who require high levels of warfarin dose to achieve therapeutic INR (> 49 $\mathrm{mg}$ /week), or normal patients, who require moderate doses (21-49 mg/week) or finally as sensitive patients who require a low dose $(<21 \mathrm{mg} /$ week). The later definition was based on the Gordon study (2009) [29]. The second concept included warfarin responses and was evaluated according to the study by Higashi et al. (2002) in patients with good response (INR value within the therapeutic range), poor response (INR value below the target range), and ultra-response (INR above the target range) [30].

\section{SNP selection and genotyping}

Candidate SNPs were selected from a public database such as the National Center for Biotechnology Information (NCBI) (http://www. ncbi.nlm.nih.gov/SNP/) and the Applied Biosystems SNP database (http:/ / www.appliedbiosystems). Five SNPs were selected from the genes CYP4F2, ApoE, and CYP2A6. Table S1 listed those genes, SNP IDs, and their locations. The DNA was extracted from the blood sample with the Wizard Genomic DNA Purification Kit (Promega), then samples that met the quantitative requirements were sent to the Australian Genome Research Facility (AGRF) to test the genotype using the MassARRAY _ system (iPLEX GOLD) (Sequenom, San Diego, CA, USA). The MassARRAYTM system protocol and the primer information used for the CYP4F2, ApoE, and CYP2A6 genes are available upon request.

\section{Statistical analysis}

To examine which of the selected polymorphisms was associated with this susceptibility to CVDs and warfarin responses, a multivariate analysis was performed, which included a chi-squared test, one-way ANOVA, Tukey HSD post hoc multiple comparison test, and non-parametric correlation test. SPSS version 21.0 was used for all analyzes.

\section{Results}

\section{Patient characteristics}

A total of 212 cardiovascular patients with warfarin treatment and 213 healthy volunteers from Jordan were included in this study. Those participants were genetically tested and clinically evaluated to assess both the association between CYP4F2, ApoE, and CYP2A6 polymorphisms and the susceptibility to cardiovascular disease and the impact of those polymorphisms on the sensitivity and responsiveness of warfarin during the initiation phase of therapy. Only $139(66 \%)$ of the patients reached the stabilization phase and, they were used to assess the genetic effects of those polymorphisms on the sensitivity and responsiveness of warfarin during the stabilization phase of therapy. In total, $69.6 \%$ of patients were found to be good metabolizers, $15.2 \%$ were extensive metabolizers and $15.2 \%$ were poor metabolizers. Patients' demographics and clinical characteristics for each group were listed in a previous study by AL-Eitan et al. (2019) [31].

\section{Genotypic and allelic frequencies}

One of the five selected SNPs was not polymorphic (Monomorphic) (rs11083750) from ApoE gene and only four SNPs were included in this study. The latter passed the quality control tests with high accuracy and a low rate of discordance. Table S2 summarizes minor allelic frequencies and Hardy Weinberg equilibrium (HWE) p-values for the 212 cardiovascular patients and the 213 healthy controls. The genotypic frequencies of the CYP4F2, ApoE, and CYP2A6 genes in the patients and controls are shown in Table 1. Only the rs7412 SNPs of the ApoE gene $(\mathrm{CC} / \mathrm{TC} / \mathrm{TT})$ and $(\mathrm{CC}(\mathrm{TC}+\mathrm{TT}))$ were significantly different between patients and controls with (P-value $=0.04)$ and $(P$-value $=0.02)$, respectively. In addition, significant associations were found between $A p o E$ haplotypes (TCG) and cardiovascular disease in patients and healthy controls with $(P$-value $<0.01)$ (Table S3).

\section{Association of CYP4F2, ApoE, and CYP2A6 polymorphisms with warfarin sensitivity during the initiation and stabilization phases of therapy}

Patients were defined as sensitive, moderate, and resistant patients, depending on the dose required to reach the therapeutic INR. All SNPs showed no significant difference between the three warfarin-sensitive groups during the initiation phase of therapy with $(P>0.05)$, except that the CYP2A6 
(rs1801272) sensitive group showed a high frequency of (TA) genotype $(60 \%)$ while wild-type (AA) was $(14 \%)$ with (overall P-value $=0.02)$ (Table 2). However, during the stabilization phase, no significant associations were found for all selected SNPs among the three sensitive groups with (P-value $>$ 0.05) (Table 3). Furthermore, no significant association was observed between ApoE haplotypes and warfarin sensitivity ( $P$-value $>0.05)$ (Table S4). There were no statistically significant differences between the doses required to reach the target INR during the initiation and stabilization phases of the treatment and the selected SNP genotypes $(\mathrm{P}>0.05)$ with the exception of (rs7412) of the ApoE gene $(P$-value $=0.02)($ Table 4$)$. Likewise, post-hock tests do not show a significant association between SNPs and the required warfarin dose $(P$-value $\leq 0.05)$ (Table S5).

Table 1. The distributions of CYP4F2, APOE and CYP2A6 SNPs in 212 cardiovascular patients and 213 healthy controls

\begin{tabular}{llllll}
\hline Gene & SNP ID & Model & Patients $\%$ & Controls $\%$ & $P$-value \\
\hline CYP4F2 & rs2108622 & CC/CT/TT & $43.9 / 42.5 / 13.7$ & $35.2 / 46.5 / 18.3$ & 0.15 \\
& & CC/(CT+TT) & $43.9 / 56.1$ & $35.2 / 64.8$ & 0.07 \\
& & (CC+CT)/TT & $86.3 / 13.7$ & $81.7 / 18.3$ & 0.19 \\
APOE & rs7412 & CC/TC/TT & $90.3 / 9.2 / 0.5$ & $96.2 / 3.8 / 0$ & 0.04 \\
& & CC(TC+TT) & $90.3 / 9.7$ & $96.2 / 3.8$ & 0.02 \\
& & (CC+TC)/TT & $99.5 / 0.5$ & $100 / 0$ & 0.24 \\
APOE & rs405509 & GG/GT/TT & $31.6 / 43.4 / 25$ & $27.2 / 51.2 / 21.6$ & 0.28 \\
& & GG/(GT+TT) $31.6 / 68.4$ & $27.2 / 72.8$ & 0.32 \\
& & (GG+GT)/TT 75/25 & $78.4 / 21.6$ & 0.41 \\
CYP2A6 & rs1801272 & AA/TA & $97.6 / 2.4$ & $96.2 / 3.8$ & 0.39 \\
\hline
\end{tabular}

${ }^{*}$ Chi-Square Test with $p<0.05$ is considered significant.

\section{Association of CYP4F2, ApoE, and CYP2A6 polymorphisms and warfarin responsiveness during initiation and stabilization phases of therapy}

According to the response to warfarin, the patients were divided into three groups: poor, good, and ultra-responders. There were no significant differences between the frequencies of the different genotypes in the three groups, in the initial phase of therapy with (P-value $>0.05)$ (Table 5). However, a significant association was found with the genetic polymorphism (rs1801272) of the CYP2A6 gene during the stabilization phase of therapy, with $50 \%$ of the (TA) genotype were poor responders and only $5.2 \%$ of the wild-type (AA) were poorly responders $(P$-value $=0.002)$. In addition, $($ rs2108622 $)$ CYP4F2 SNP showed a significant association between the distribution of the (CT) genotype among the three responder groups $(P$-value $=0.04)$ (Table 6), While no significant associations were found between the ApoE genetic haplotypes and the ability to respond to warfarin (P-value $>0.05)$ (Table S6). There were no significant differences between the selected SNPs and the INR values that were measured in the initial phase of therapy in the 212 patients receiving warfarin $(P$-value $>0.05)$. However, differences were found between CYP2A6 (rs1801272) and the INR values that were measured in the 139 patients during the stabilization phase with (overall P-value $=0.02$ ) (Tables 7 and S7).

Table 2. Associations of CYP4F2, APOE and CYP2A6 SNPs with warfarin sensitivity during the initiation phase of therapy of 212 cardiovascular patients treated with warfarin

\begin{tabular}{|c|c|c|c|c|c|c|}
\hline Gene & SNP ID & Genotype & Sensitive ${ }^{a}$ & Moderate & Resistance $^{c}$ & $\begin{array}{l}\text { Overall } \\
P \text {-value* }\end{array}$ \\
\hline \multirow[t]{8}{*}{ CYP4F2 } & rs2108622 & $\mathrm{CC}$ & $(19 / 93)$ & $(62 / 93)$ & $(12 / 93)$ & 0.18 \\
\hline & & & $20.4 \%$ & $66.7 \%$ & $12.9 \%$ & \\
\hline & & $P$-value* & 0.16 & 0.83 & 0.55 & \\
\hline & & $\mathrm{CT}$ & $(10 / 90)$ & $(61 / 90)$ & $(19 / 90)$ & \\
\hline & & & $11.1 \%$ & $67.8 \%$ & $21.1 \%$ & \\
\hline & & $P$-value* & 0.38 & 0.96 & 0.22 & \\
\hline & & $\mathrm{TT}$ & $\begin{array}{l}(3 / 29) \\
10.3 \%\end{array}$ & $\begin{array}{l}(23 / 29) \\
79.3 \%\end{array}$ & (3/29) $10.3 \%$ & \\
\hline & & $P$-value* & 0.74 & 0.43 & 0.67 & \\
\hline \multirow[t]{7}{*}{$A P O E$} & rs7412 & $\mathrm{CC}$ & $(28 / 187)$ & $(129 / 187)$ & $(30 / 187)$ & 0.94 \\
\hline & & & $15 \%$ & $69 \%$ & $16 \%$ & \\
\hline & & $P$-value* & 1 & 0.95 & 0.9 & \\
\hline & & TC & $\begin{array}{l}(3 / 19) \\
15.8 \%\end{array}$ & $\begin{array}{l}(12 / 19) \\
63.2 \%\end{array}$ & (4/19) $21.1 \%$ & \\
\hline & & $P$-value* & 1 & 0.86 & 0.86 & \\
\hline & & TT & (0/1) $0.0 \%$ & (1/1) $100 \%$ & $(0 / 1) 0.0 \%$ & \\
\hline & & $P$-value* & 0.90 & 0.78 & 0.9 & \\
\hline \multirow[t]{6}{*}{$A P O E$} & rs405509 & GG & $\begin{array}{l}(13 / 67) \\
19.4 \%\end{array}$ & $\begin{array}{l}(43 / 67) \\
64.2 \%\end{array}$ & $\begin{array}{l}(11 / 67) \\
16.4 \%\end{array}$ & 0.59 \\
\hline & & $P$-value* & 0.49 & 0.61 & 1 & \\
\hline & & GT & $\begin{array}{l}(12 / 92) \\
13.0 \%\end{array}$ & $\begin{array}{l}(63 / 92) \\
68.5 \%\end{array}$ & $\begin{array}{l}(17 / 92) \\
18.5 \%\end{array}$ & \\
\hline & & $P$-value* & 0.77 & 1 & 0.70 & \\
\hline & & $\mathrm{TT}$ & $\begin{array}{l}(7 / 53) \\
13.2 \%\end{array}$ & $\begin{array}{l}(40 / 53) \\
75.5 \%\end{array}$ & (6/53) $11.3 \%$ & \\
\hline & & $P$-value* & 0.90 & 0.49 & 0.56 & \\
\hline \multirow[t]{4}{*}{ CYP2A6 } & rs1801272 & $\mathrm{AA}$ & $\begin{array}{l}(29 / 207) \\
14 \%\end{array}$ & $\begin{array}{l}(145 / 207) \\
70 \%\end{array}$ & $\begin{array}{l}(33 / 207) \\
16 \%\end{array}$ & 0.02 \\
\hline & & $P$-value* & 0.02 & 0.06 & 0.97 & \\
\hline & & TA & $(3 / 5) 60 \%$ & (1/5) $20 \%$ & (1/5) $20 \%$ & \\
\hline & & $P$-value* & 0.02 & 0.06 & 0.97 & \\
\hline
\end{tabular}

${ }^{*}$ Chi-square test with $p$ value $<0.05$ is considered significant.

a Warfarin Sensitive group (required minimum warfarin dose $<21 \mathrm{mg} /$ week). b Warfarin Moderate response group (required average warfarin dose between 21 and $49 \mathrm{mg}$ /week).

c Warfarin Resistance group (required high warfarin dose $>49 \mathrm{mg} /$ week).

\section{Discussion}

In the current study, we examined and characterized the relationship between polymorphisms of the CYP4F2, ApoE, and CYP2A6 genes and the increased risk of cardiovascular diseases, in addition to their relation with the sensitivity and responsiveness to warfarin during the initiation and stabilization phases of therapy in a Jordanian population. Regarding the relationship between those polymorphisms and the susceptibility to cardiovascular diseases, only one of the four investigated SNPs, (rs7412) ApoE gene, displayed significant association. According to our results, it was found that $9.7 \%$ of patients with CVDs were 
homogeneous or heterogeneous of the mutant allele (T) compared to only $3.8 \%$ in the control group. Many reports support the effect of this SNP on increasing the susceptibility for CVD. For instance, it was associated with increased BMI and Waist Girth [32]. As well, it was associated with increased levels of LDL-C and TC [33].

Table 3. Associations of CYP4F2, APOE and CYP2A6 SNPs with warfarin sensitivity during the stabilization phase of therapy of 139 cardiovascular patients treated with warfarin

\begin{tabular}{|c|c|c|c|c|c|c|}
\hline Gene & SNP ID & Genotype & Sensitive ${ }^{a}$ & Moderate $^{b}$ & Resistance $^{c}$ & $\begin{array}{l}\text { Overall } \\
P \text {-value* }\end{array}$ \\
\hline \multirow[t]{7}{*}{ CYP4F2 } & rs2108622 & . CC & $(10 / 61)$ & $(39 / 61)$ & $(12 / 61)$ & 0.66 \\
\hline & & & $16.4 \%$ & $63.9 \%$ & $19.7 \%$ & \\
\hline & & $P$-value* & 0.84 & 0.90 & 0.61 & \\
\hline & & $\mathrm{CT}$ & (9/59) 15.3\% & $\begin{array}{l}(35 / 59) \\
59.3 \%\end{array}$ & $\begin{array}{l}(15 / 59) \\
25.4 \%\end{array}$ & \\
\hline & & $P$-value* & 0.97 & 0.87 & 0.92 & \\
\hline & & TT & (1/19) 5.3\% & $\begin{array}{l}(12 / 19) \\
63.2 \%\end{array}$ & $(6 / 19) 31.6 \%$ & \\
\hline & & $P$-value* & 0.47 & 0.99 & 0.69 & \\
\hline \multirow[t]{4}{*}{$A P O E$} & rs7412 & $\mathrm{CC}$ & $\begin{array}{l}(17 / 122) \\
13.9 \%\end{array}$ & $\begin{array}{l}(76 / 122) \\
62.3 \%\end{array}$ & $\begin{array}{l}(29 / 122) \\
23.8 \%\end{array}$ & 0.67 \\
\hline & & $P$-value* & 0.68 & 0.84 & 1 & \\
\hline & & $\mathrm{TC}$ & (3/13) $23.1 \%$ & (7/13) 53.8\% & (3/19) $23.1 \%$ & \\
\hline & & $P$-value* & 0.68 & 0.84 & 1 & \\
\hline \multirow[t]{6}{*}{$A P O E$} & rs405509 & GG & $(8 / 42) 19 \%$ & $(29 / 42) 69 \%$ & (5/42) $12 \%$ & 0.24 \\
\hline & & $P$-value* & 0.1 & 0.52 & 0.59 & \\
\hline & & GT & (7/61) $11.5 \%$ & $\begin{array}{l}(35 / 61) \\
57.4 \%\end{array}$ & $\begin{array}{l}(19 / 61) \\
31.1 \%\end{array}$ & \\
\hline & & $P$-value* & 0.69 & 0.63 & 0.19 & \\
\hline & & TT & $(5 / 36) 13.9 \%$ & $\begin{array}{l}(22 / 36) \\
61.1 \%\end{array}$ & (9/36) $25 \%$ & \\
\hline & & $P$-value* & 1 & 1 & 0.98 & \\
\hline \multirow[t]{4}{*}{ CYP2A6 } & rs1801272 & AA & $\begin{array}{l}(18 / 135) \\
13.3 \%\end{array}$ & $(85 / 135) 63 \%$ & $\begin{array}{l}(32 / 135) \\
23.7 \%\end{array}$ & 0.10 \\
\hline & & $P$-value* & 0.12 & 0.31 & 1 & \\
\hline & & TA & (3/4) $50 \%$ & (1/4) $25 \%$ & (1/4) $25 \%$ & \\
\hline & & $P$-value* & 0.12 & 0.31 & 1 & \\
\hline
\end{tabular}

${ }^{*}$ Chi-square test with $p$ value $<0.05$ is considered significant.

a Warfarin Sensitive group (required minimum warfarin dose $<21 \mathrm{mg} /$ week).

b Warfarin Moderate response group (required average warfarin dose between 21 and $49 \mathrm{mg}$ /week)

c Warfarin Resistance group (required high warfarin dose $>49 \mathrm{mg} /$ week).

In comparison to other studies, which focused mainly on the ApoE haplotype (rs7412, rs429358) instead of individual SNPs in the ApoE gene, the study of Lahoz et al (2011) showed that variations of the ApoE E2 (represented by rs7412 (T) allele and rs429358 (T) allele) and E4 (represented by rs7412 (C) allele and rs429358 (C) allele in the gene compared to the E3: E3 genotype may play a gender-specific role in CVD risk, with an increased risk of disease in men with E2 and E4 alleles [12].

Otherwise, Saudi and Taiwanese studies did not expose a statistically significant difference in the distribution of genotypes or alleles between patients with CVD and control groups according to the E2 ApoE haplotype. The Saudi E2 was closely associated with classic predictors of atherosclerosis [34, 35]. In disagreement with our findings, the study by Viitanen et al. (2001) indicated that there is an increased risk of
CVD in patient's carriers of the $(\mathrm{T})$ variant allele of the rs405509 gene polymorphism, while our study did not show a significant association between this SNP and the risk of CVD [36]. Moreover, our result didn't show significant differences in the distribution of genotypic frequency of rs2108622 CYP4F2 SNP between patients and control and this finding was inconsistent with the result of Yan et al. (2015) which found that the variant allele of rs2108622 was significantly higher in the patient with IS than in the control group [10]. Possibly, the differences in ethnicities, the underlying ischemic diseases, the disease stages, and other factors may contribute to such differences.

Table 4. Association of CYP4F2, APOE and CYP2A6 SNPs with variability on warfarin required doses

\begin{tabular}{lllllll}
\hline Gene & SNP ID & Genotype & $\begin{array}{l}\text { Initiation } \\
\text { dose }\end{array}$ & $\begin{array}{l}\text { Overall } \\
P \text {-value* }\end{array}$ & $\begin{array}{l}\text { Maintenance } \\
\text { dose }\end{array}$ & $\begin{array}{l}\text { Overall } \\
P \text {-value }^{*}\end{array}$ \\
\hline \multirow{2}{*}{ CYP4F2 } & rs2108622 & CT & $38.87[15.45]$ & & $36.66[17.11]$ & \\
& & TT & $44.59[4.67 .83]$ & 0.21 & $40.24[19.99]$ & 0.54 \\
& & CC & $36.79[14.33]$ & & $39.43[12.76]$ & \\
APOE & rs74125 & TC & $53.39[62.10]$ & 0.02 & $38.60[25.09]$ & 0.48 \\
& & TT & $38.40[\ldots \ldots .$. & & & \\
& & GG & $38.13[37.72]$ & & $35.49[17.74]$ & \\
APOE & rs405509 & GT & $38.28[15.55]$ & 0.98 & $41.01[18.36]$ & 0.30 \\
& & TT & $37.60[14.39]$ & & $37.98[17.04]$ & \\
CYP2A6 & rs1801272 & AA & $38.16[22.83]$ & 0.67 & $38.56[16.79]$ & 0.99 \\
& & TA & $33.64[34.87]$ & & $38.60[45.86]$ & \\
\hline
\end{tabular}

*One-way ANOVA test with $P$-value $<0.05$ is considered significant, Mean

Standard deviation in square brackets.

Regarding the pharmacogenetic part of this study, numerous warfarin pharmacogenetic studies indicated that the common polymorphisms of VKORC1 and CYP2C9 together with environmental and clinical factors account for more than half of the variation in the required warfarin dose [37, 38]. We have recently published a study examining the effects of genetic polymorphism of CYP2C9, VKORC1, FVII, PSRC1, CELSR2, and SORT1 on the sensitivity and responsiveness to warfarin treatment during the initiation and stabilization phase of therapy in Jordanian Arab cardiovascular patients [26, 27, 39, 40]. In this study, our goal was to expand our knowledge and identify other genetic factors associated with warfarin sensitivity and response, including the CYP4F2, ApoE, and CYP2A6 genes. The results of the current pharmacogenetic study strongly suggest that there is a significant association of CYP2A6 rs1801272 SNP with warfarin sensitivity and between ApoE rs7412 SNP and the variability of the warfarin required dose during the initiation phase of therapy. This study also reported that there is a genetic association between CYP2A6 rs1801272 SNP and the ability to respond to warfarin and INR measurements during the stabilization phase of therapy. Few studies reported a direct effect of those SNPs on warfarin 
metabolism. For instance, according to some reports, the CYP2A6 (which is sometimes called a human coumarin 7-hydroxylase) rs1801272 SNP was associated with no activity effect on the protein and therefore can modulate its effect on the warfarin metabolism [41]. On the other hand, other studies from the region reported no effect of the APOE SNPs including the rs7412 SNP in warfarin dose adjustment [42] while other Asian studies on Chinese people showed positive associations [43].

Table 5. Association of CYP4F2, APOE and CYP2A6 SNPs with warfarin responsiveness during the initiation phase of therapy of 212 cardiovascular patients treated with warfarin

\begin{tabular}{|c|c|c|c|c|c|c|}
\hline Gene & SNP ID & Genotype & $\begin{array}{l}\text { Poor } \\
\text { responders }\end{array}$ & $\begin{array}{l}\text { Good } \\
\text { responders }\end{array}$ & $\begin{array}{l}\text { Ultra } \\
\text { respondersc }\end{array}$ & $\begin{array}{l}\text { Overall } \\
P \text {-value* }\end{array}$ \\
\hline \multirow[t]{6}{*}{ CYP4F2 } & rs2108622 & $\mathrm{CC}$ & (17/93) 18.3\% & $\begin{array}{l}(72 / 93) \\
77.4 \%\end{array}$ & $(4 / 93) 4.3 \%$ & 0.54 \\
\hline & & $P$-value* & 1 & 0.95 & 0.88 & \\
\hline & & $\mathrm{CT}$ & (17/90) 18.9\% & $\begin{array}{l}(66 / 90) \\
73.3 \%\end{array}$ & (7/90) $7.8 \%$ & \\
\hline & & $P$-value ${ }^{*}$ & 0.99 & 0.66 & 0.34 & \\
\hline & & TT & (5/29) $17.2 \%$ & $\begin{array}{l}(24 / 29) \\
82.8 \%\end{array}$ & (0/29) $0.0 \%$ & \\
\hline & & $P$-value* & 0.99 & 0.69 & 0.40 & \\
\hline \multirow[t]{6}{*}{$A P O E$} & rs7412 & $\mathrm{CC}$ & $\begin{array}{l}(34 / 187) \\
18.2 \%\end{array}$ & $\begin{array}{l}(143 / 187) \\
76.5 \%\end{array}$ & $\begin{array}{l}(10 / 187) \\
5.3 \%\end{array}$ & 0.25 \\
\hline & & $P$-value ${ }^{*}$ & 0.76 & 0.99 & 0.57 & \\
\hline & & $\mathrm{TC}$ & (4/19) $21.1 \%$ & $\begin{array}{l}(15 / 19) \\
78.9 \%\end{array}$ & (0/19) $0.0 \%$ & \\
\hline & & $P$-value* & 0.97 & 0.96 & 0.59 & \\
\hline & & TT & $(1 / 1) 100 \%$ & (0/1) $0.0 \%$ & (0/1) $0.0 \%$ & \\
\hline & & $P$-value* & 0.11 & 0.20 & 0.98 & \\
\hline \multirow[t]{6}{*}{$A P O E$} & rs405509 & GG & (14/67) $20.9 \%$ & $\begin{array}{l}(51 / 67) \\
76.1 \%\end{array}$ & $(2 / 67) 3 \%$ & 0.55 \\
\hline & & $P$-value* & 0.81 & 1 & 0.62 & \\
\hline & & GT & (16/92) $17.4 \%$ & $\begin{array}{l}(72 / 92) \\
78.3 \%\end{array}$ & (4/92) $4.3 \%$ & \\
\hline & & P-value* & 0.95 & 0.86 & 0.89 & \\
\hline & & TT & $(9 / 53) 17 \%$ & $\begin{array}{l}(39 / 53) \\
73.6 \%\end{array}$ & (5/53) $9.4 \%$ & \\
\hline & & $P$-value* & 0.96 & 0.86 & 0.27 & \\
\hline \multirow[t]{4}{*}{ CYP2A6 } & rs1801272 & $\mathrm{AA}$ & $\begin{array}{l}(37 / 207) \\
17.9 \%\end{array}$ & $\begin{array}{l}(159 / 207) \\
76.8 \%\end{array}$ & $\begin{array}{l}(11 / 207) \\
5.3 \%\end{array}$ & 0.42 \\
\hline & & $P$-value* & 0.45 & 0.68 & 0.87 & \\
\hline & & TA & (2/5) $40 \%$ & $(3 / 5) 60 \%$ & $(0 / 5) 0 \%$ & \\
\hline & & $P$-value* & 0.45 & 0.68 & 0.87 & \\
\hline
\end{tabular}

${ }^{*}$ Chi-Square Test with $p$ value $<0.05$ is considered significant.

a Poor responders (INR value below target).

$\mathrm{b}$ Good responders who have an INR value in the target range (therapeutic range) c Ultra responders (INR over target).

The minor allele frequency of CYP4F2 rs2108622 SNP in our population was $38 \%$, which is similar to that found in white and Asian ethnic groups, while it differs from the black ethnic group with only $7 \%$ [44]. According to Jarrar et al., a high frequency of CYP4F2 rs2108622 SNP was observed among healthy Arab Jordanians [45]. However, Caldwell et al (2019) study revealed that patients carrier for $(\mathrm{T})$ variant allele decrease the CYP4F2 enzyme activity and therefore lead to an increase in the warfarin required dose [44]. Moreover, a study in the Japanese population showed that the average daily warfarin dose in the CYP4F2
(CT/ TT) carriers were $28.2 \%$ higher than in the CYP4F2 (CC) wild-type carriers [46]. Accordingly, our finding showed that the patient homozygous for the variant allele (TT) had required a weakly warfarin dose of 44.59 [49.83] mg compared to 35.87 [15.45] $\mathrm{mg} /$ weak for the wild-type (CC) allele during the initial stages of the therapy, but this was not statistically significant (Table 4). Moreover, when comparing the three sensitive groups (sensitive, moderate, and resistant) during the stabilization phase of the therapy, our results also implicated that $31.6 \%$ of the resistance group were (TT) carriers and $25.4 \%$ were (CT) carriers in comparison to $19.7 \%$ of them who were (CC) carriers for wild-type allele, therefore patients with (TT) and (CT) polymorphisms needed higher doses of warfarin to achieve their therapeutic effect, but again this was not statistically significant (Table 3). However, when comparing the three responder groups (poor, good, and ultra), this SNP showed no differences between the three responder groups and with the INR measurements during the initiation and stabilization phase of the therapy, which was consistent with the Japanese study, indicating that the mean PT-INR values were not differentiated between the CYP4F2 genotypes [46].

Table 6. Association of CYP4F2, APOE and CYP2A6 SNPs with warfarin responsiveness during the stabiliaiztaion phase of therapy of 139 cardiovascular patients treated with warfarin

\begin{tabular}{|c|c|c|c|c|c|c|}
\hline Gene & SNP ID & Genotype & $\begin{array}{l}\text { Poor } \\
\text { respondera }\end{array}$ & $\begin{array}{l}\text { Good } \\
\text { responderb }\end{array}$ & $\begin{array}{l}\text { Ultra } \\
\text { responderc }\end{array}$ & $\begin{array}{l}\text { Overall } \\
P \text {-value* }\end{array}$ \\
\hline & & $\mathrm{CC}$ & $(2 / 61) 3.3 \%$ & (57/61) 93.4\% & $(2 / 61) 3.3 \%$ & 0.12 \\
\hline \multirow[t]{6}{*}{ CYP4F2 } & rs2108622 & $P$-value* & 0.40 & 0.36 & 0.87 & \\
\hline & & $\mathrm{CT}$ & $\begin{array}{l}(7 / 59) \\
11.9 \%\end{array}$ & (48/59) $81.4 \%$ & (4/59) $6.8 \%$ & \\
\hline & & $P$-value* & 0.09 & 0.04 & 0.47 & \\
\hline & & $\mathrm{TT}$ & (0/19) $0 \%$ & (19/19) 100\% & (0/19) $0 \%$ & \\
\hline & & $P$-value* & 0.47 & 0.26 & 0.61 & \\
\hline & & $\mathrm{CC}$ & $\begin{array}{l}(8 / 122) \\
6.6 \%\end{array}$ & $\begin{array}{l}(108 / 122) \\
88.5 \%\end{array}$ & $\begin{array}{l}(6 / 122) \\
4.9 \%\end{array}$ & 0.71 \\
\hline \multirow[t]{5}{*}{$A P O E$} & rs7412 & $P$-value* & 0.99 & 0.92 & 0.72 & \\
\hline & & TC & $(1 / 13) 7.7 \%$ & (12/13) 92.3\% & (0/19) $0 \%$ & \\
\hline & & $P$-value* & 0.99 & 0.92 & 0.72 & \\
\hline & & GG & (3/42) $7.1 \%$ & (38/42) 90.5\% & (1/42) $2.4 \%$ & \\
\hline & & $P$-value* & 0.98 & 0.95 & 0.76 & \\
\hline \multirow[t]{4}{*}{$A P O E$} & rs405509 & GT & (3/61) 4.9\% & (56/61) $91.8 \%$ & (2/61) 3.3\% & \\
\hline & & $P$-value* & 0.80 & 0.68 & 0.87 & 0.64 \\
\hline & & TT & (3/36) $8.3 \%$ & (30/36) 83.4\% & (3/36) $8.3 \%$ & \\
\hline & & $P$-value* & 0.87 & 0.42 & 0.39 & \\
\hline \multirow[t]{4}{*}{ CYP2A6 } & rs1801272 & AA & $\begin{array}{l}(7 / 135) \\
5.2 \%\end{array}$ & $\begin{array}{l}(122 / 135) \\
90.4 \%\end{array}$ & $\begin{array}{l}(6 / 135) \\
4.4 \%\end{array}$ & 0.002 \\
\hline & & $P$-value* & $<0.0001$ & 0.04 & 0.91 & \\
\hline & & TA & (2/4) $50 \%$ & (2/4) $50 \%$ & (0/4) $0 \%$ & \\
\hline & & $P$-value* & $<0.0001$ & 0.04 & 0.91 & \\
\hline
\end{tabular}

${ }^{*}$ Chi-Square Test with $p$ value $<0.05$ is considered significant.

a Poor responders (INR value below target).

$\mathrm{b}$ Good responders who have an INR value in the target range (therapeutic range).

c Ultra responders (INR over target). 
Table 7. Association of CYP4F2, APOE and CYP2A6 SNPs with INR treatment outcome

\begin{tabular}{|c|c|c|c|c|c|c|}
\hline Gene & SNP ID & Genotype & $\begin{array}{l}\text { Initiation } \\
\text { INR }\end{array}$ & $\begin{array}{l}\text { Overall } \\
P \text {-value* }\end{array}$ & $\begin{array}{l}\text { Maintenance } \\
\text { INR }\end{array}$ & $\begin{array}{l}\text { Overall } \\
P \text {-value* }\end{array}$ \\
\hline & & $\mathrm{CC}$ & $2.47[0.77]$ & & $2.69[0.38]$ & \\
\hline \multirow[t]{3}{*}{ CYP4F2 } & rs2108622 & CT & $2.50[0.81]$ & 0.34 & $2.70[0.41]$ & 0.97 \\
\hline & & TT & $2.27[0.61]$ & & $2.69[0.35]$ & \\
\hline & & $\mathrm{CC}$ & $2.45[0.75]$ & & $2.71[0.39]$ & \\
\hline \multirow[t]{3}{*}{$A P O E$} & rs74125 & $\mathrm{TC}$ & $2.37[0.79]$ & 0.29 & $2.49[0.34]$ & 0.06 \\
\hline & & TT & $1.30[\ldots \ldots .]$. & & & \\
\hline & & GG & $2.45[0.83]$ & & $2.69[0.43]$ & \\
\hline \multirow[t]{2}{*}{$A P O E$} & rs405509 & GT & $2.43[0.78]$ & 0.82 & $2.69[0.36]$ & 0.99 \\
\hline & & TT & $2.51[0.69]$ & & $2.70[0.40]$ & \\
\hline \multirow[t]{2}{*}{ СУР2A6 } & rs1801272 & $\mathrm{AA}$ & $2.44[0.77]$ & 0.09 & $2.71[0.38]$ & 0.02 \\
\hline & & TA & $3.02[0.81]$ & & $2.25[0.44]$ & \\
\hline
\end{tabular}

*One-way ANOVA test with $P$-value $<0.05$ is considered significant, Mean Standard deviation in square brackets.

As mentioned earlier, most studies focused mainly on the ApoE haplotype (rs7412, rs429358) instead of individual SNPs in the ApoE gene. However, although some studies showed a significant association between the allelic variant ApoE E4 and the higher dose of warfarin [24, 47], other studies have demonstrated that there is no association between warfarin dose and $A p o E$ variants [48-50]. In addition, a study in the Egyptian population showed that ApoE E2 variants were significantly associated with the lowest warfarin dose [51]. In this study, we observed that the ApoE (T) allele (rs7412) at the initiation of treatment was significantly associated with higher warfarin dose requirements, the patient with the (CT) allele received 53.39 [62.10] $\mathrm{mg} /$ weak compared to $36.79[14,33] \mathrm{mg} /$ weak in $(\mathrm{CC})$ carriers (P-value $=0.02)$ (Table 3).

However, there were no significant differences between this SNP and the sensitivity or responses to warfarin during the initiation or stabilization phase of therapy. According to the literature on ApoE gene, there was a significant relationship between re405509 and susceptibility to CVD, Alzheimer's disease, and obstructive sleep apnea in children $[36,52,53]$, but to our knowledge, no study was conducted to evaluate the effect of this SNP on the warfarin sensitivity and responsiveness. Again, our result showed no significant difference between this SNP and the sensitivity or the response to warfarin during the initial or stabilization phase of therapy. The frequency of minor alleles of CYP2A6 rs1801272 SNP in our population was $1.5 \%$, which was consistent with that found in African-American and Brazilian ethnic groups with $1.1 \%$ and $1.7 \%$, respectively, and it was less than what was found in the Chinese population with $2.2 \%$ and more than Egyptian and Japanese population with $0.7 \%$ and $0.0 \%$, respectively [54]. According to the study conducted in the Canadian population, patients with allelic polymorphisms (T) variants are associated with a greater sensitivity to warfarin and, therefore, lead to a significant reduction in the weekly dose of warfarin [55]. Correspondingly, in our study, a significant association was observed between this SNP and warfarin sensitivity, with $60 \%$ of warfarin-sensitive patients were heterozygous for the variant allele (TA) at the initiation of therapy $(P$-value $=0.02)($ Table 2$)$ and therefore, these patients required 33.64 [34.87] $\mathrm{mg} /$ weak of warfarin dose compared to 38.16 [22.83] mg/weak for wild-type carriers (Table 4). Furthermore, our result showed a significant difference between this SNP and the responsiveness to warfarin during the stabilization phase of therapy with $50 \%$ of poor responder patients were heterozygous for the variant allele (TA) and therefore the INR values have differed significantly between the (TA) carrier patients and the (AA) wild-type with $(P$-value $=0.02)($ Tables 6 and 7$)$. This result may be explained by the effect of this variant in substantially reducing the activity of the CYP2A6 enzyme [56]. However, we cannot anticipate the exact effect of this reduction on the enzymatic metabolism of warfarin, especially that warfarin can be metabolized through other pathways and the effect can be compensated by the action of other enzymes.

\section{Conclusion}

Our data show a significant association between the ApoE rs7412 SNP and the risk of CVD in the Jordanian population. Moreover, ApoE rs7412 SNP exhibited significant differences in warfarin initial doses. As well, a significant association was found between the CYP2A6 rs1801272 polymorphism and warfarin sensitivity during the initiation phase of therapy and with warfarin responsiveness and INR measurement during the stabilization phase of therapy. To confirm our results, further studies with a large number of samples and different populations are required. Personalized warfarin prescription can be a safe and effective anticoagulation therapy for patients with cardiovascular disease. Therefore, more pharmacogenetic studies are needed to evaluate the effects of other clinical and genetic factors, thereby facilitating the prevention and treatment of cardiovascular disease.

\section{Supplementary Material}

Supplementary tables.

http://www.medsci.org/v18p0826s1.pdf

\section{Acknowledgments}

We thank the Anti-coagulant clinic in Queen Alia Heart Institute for their generous help during the course of this study. 


\section{Funding}

This project was supported by the Deanship of Research at Jordan University of Science and Technology under grant number $(203 / 2014)$.

\section{Competing Interests}

\section{interest exists.}

\section{References}

1. Elhneiti M, Al-Hussami M. Predicting Risk Factors of Heart Disease among Jordanian Patients. Health. 2017; 9(2): 237-251.

2. [Internet] WHO. Cardio-Vascular Diseases. 2017; 1-6. Available from: https://www

who.int/news-room/fact-sheets/detail/cardiovascular-diseases-(cvds).

3. Deloukas P, Kanoni S, Willenborg C, et al. Large-scale association analysis identifies new risk loci for coronary artery disease. Nature Genetics. 2013; 45(1): 25-33.

4. Sing CF, Davignon J. Role of the apolipoprotein E polymorphism in determining normal plasma lipid and lipoprotein variation. Am J Hum Genet. 1985; 37(2): 268-285.

5. Havel RJ. Familial dysbetalipoproteinemia. New aspects of pathogenesis and diagnosis. Med Clin North Am. 1982; 66(2): 441-454.

6. Hunter AL, Cruz RP, Cheyne BM, et al. Cytochrome p450 enzymes and cardiovascular disease. Can J Physiol Pharmacol. 2004; 82(12): 1053-1060.

7. Yu C, Yan Q, Fu C, et al. CYP4F2 genetic polymorphisms are associated with coronary heart disease in a Chinese population. Lipids Health Dis. 2014; 13(1):1-5.

8. Tatarunas V, Kupstyte N, Giedraitiene A, et al. The impact of CYP2C19 *2, CYP4F2 $* 3$, and clinical factors on platelet aggregation, CYP4F2 enzyme activity, and 20-hydroxyeicosatetraenoic acid concentration in patients treated with dual antiplatelet therapy. Blood Coagul Fibrinolysis. 2017; 28(8): 658-664.

9. Stec DE, Roman RJ, Flasch A, et al. Functional polymorphism in human CYP4F2 decreases 20-HETE production. Physiological genomics. 2007; (3): 74-81.

10. Yan HQ, Yuan $Y$, Zhang $P$, et al. CYP4F2 gene single nucleotide polymorphism is associated with ischemic stroke. Genet Mol Res. 2015; 14(1): 659-664.

11. Lamia LF, Sharif FA, Abed AA. Relationship between ApoE gene polymorphism and coronary heart disease in Gaza Strip. J Cardiovasc Dis Res. 2011; 2(1): 29-35.

12. Lahoz C, Schaefer EJ, Cupples LA, et al. Apolipoprotein E genotype and cardiovascular disease in the Framingham Heart Study. Atherosclerosis. 2001; 154(3): 529-537.

13. Koskela S, Hakkola J, Hukkanen J, et al. Expression of CYP2A genes in human liver and extrahepatic tissues. Biochem Pharmacol. 1999; 57(12): 1407-1413.

14. McDonagh EM, Wassenaar C, David SP, et al. PharmGKB summary. Pharmacogenet Genomics. 2012; 22(9): 695-708.

15. Loukola A, Buchwald J, Gupta R, et al. A Genome-Wide Association Study of a Biomarker of Nicotine Metabolism. PLoS Genet. 2015; 11(9): 1-23.

16. Ansell J, Hirsh J, Hylek E, et al. Pharmacology and management of the vitamin K antagonists: American College of Chest Physicians Evidence-Based Clinical Practice Guidelines (8th Edition). Chest. 2008; 133(6): 160S-198S.

17. Kaminsky LS, Zhang ZY. Human P450 metabolism of warfarin. Pharmacol Ther. 1997; 73(1): 67-74.

18. Johnson JA, Cavallari LH. Warfarin pharmacogenetics. Trends Cardiovasc Med. 2015; 25(1): 33-41.

19. Effect of long-term oral anticoagulant treatment on mortality and cardiovascular morbidity after myocardial infarction. Anticoagulants in the Secondary Prevention of Events in Coronary Thrombosis (ASPECT) Research Group. Lancet (London, England) 1994; 343(8896): 499-503.

20. Linkins LA, Choi PT, Douketis JD. Clinical Impact of Bleeding in Patients Taking Oral Anticoagulant Therapy for Venous Thromboembolism: A Meta-Analysis. Ann Intern Med. 2003; 139(11): 893-900.

21. Gage BF, Lesko LJ. Pharmacogenetics of warfarin: Regulatory, scientific, and clinical issues. J Thromb Thrombolysis. 2008; 25(1): 45-51.

22. Al-eitan LN, Haddad YA. Emergence of Pharmacogenomics in Academic Medicine and Public Health in Jordan: History, Present State and Prospects. Current Pharmacogenomics and Personalized Medicine (Formerly Current Pharmacogenomics). 2014; 12(3): 167-175.

23. AL-Eitan LN, Tarkhan AH. Practical Challenges and Translational Issues in Pharmacogenomics and Personalized Medicine from 2010 Onwards. Current Pharmacogenomics and Personalized Medicine (Formerly Current Pharmacogenomics). 2016; 14(1): 7-17.

24. Wadelius M, Chen LY, Eriksson N, et al. Association of warfarin dose with genes involved in its action and metabolism. Hum Genet. 2007; 121(1): 23-34.

25. Wallin R, Hutson SM. Warfarin and the vitamin K-dependent $\gamma$-carboxylation system. Trends Mol Med. 2004; 10(7): 299-302.
26. AL-Eitan L, Almasri A, Khasawneh R. Impact of CYP2C9 and VKORC1 Polymorphisms on Warfarin Sensitivity and Responsiveness in Jordanian Cardiovascular Patients during the Initiation Therapy. Genes. 2018; 9(12): 578.

27. AL-Eitan LN, Almasri AY, Khasawneh RH. Effects of CYP2C9 and VKORC1 polymorphisms on warfarin sensitivity and responsiveness during the stabilization phase of therapy. Saudi Pharm J. 2019; 27(4): 484-490.

28. D'Andrea G, D'Ambrosio R, Margaglione M. Oral anticoagulants: Pharmacogenetics. Relationship between genetic and non-genetic factors. Blood Rev. 2008; 22(3): 127-140.

29. Gordon MS. Estimation of the Warfarin Dose with Clinical and Pharmacogenetic Data. N. Engl. J. Med. 2009; 360(8): 753-764.

30. Higashi MK, Veenstra DL, Kondo LM, et al. Association between CYP2C9 genetic variants and anticoagulation-related outcomes during warfarin therapy. Jama. 2002; 287(13): 1690-1698.

31. AL-Eitan LN, Almasri AY, Al-habahbeh SO. Impact of a variable number tandem repeat in the CYP2C9 promoter on warfarin sensitivity and responsiveness in Jordanians with cardiovascular disease. Pharmgenomics Pers Med. 2019; 12:15-22.

32. Ejedor MT, Garcia-Sobreviela MP, Ledesma M, Arbones-Mainar JM. The apolipoprotein E polymorphism rs7412 associates with body fatness independently of plasma lipids in middle aged men. PLoS One. 2014;9(9):e108605.

33. Chang MH, Yesupriya A, Ned RM, Mueller PW, Dowling NF. Genetic variants associated with fasting blood lipids in the U.S. population: Third National Health and Nutrition Examination Survey. BMC Med Genet. 2010;11:62.

34. Dzimiri N, Meyer BF, Hussain SS, et al. Relevance of Apolipoprotein E Polymorphism for Coronary Artery Disease in the Saudi Population. Archives of pathology \& laboratory medicine. 1999; 123(12): 1241-1245.

35. Wu JH, Lo SK, Wen MS, et al. Characterization of apolipoprotein E genetic variations in Taiwanese: association with coronary heart disease and plasma lipid levels. Human biology. 2002; 74(1): 25-31.

36. Viitanen L, Pihlajam J, Miettinen R, et al. Apolipoprotein E gene promoter (219G/T ) polymorphism is associated with premature coronary heart disease. Journal of molecular medicine. 2001; 79(12): 732-737.

37. Wiedermann CJ, Stockner I. Warfarin-induced bleeding complications-clinical presentation and therapeutic options. Thrombosis Research. 2008; 122: S13-S18.

38. Borgiani $\mathrm{P}$, Ciccacci $\mathrm{C}$, Forte $\mathrm{V}$, et al. Allelic variants in the CYP2C9 and VKORC1 loci and interindividual variability in the anticoagulant dose effect of warfarin in Italians. Pharmacogenomics. 2007; 8(11): 1545-1550.

39. Al-Eitan LN, Almasri AY, Al-Habahbeh SO. Effects of coagulation factor VII polymorphisms on warfarin sensitivity and responsiveness in Jordanian cardiovascular patients during the initiation and maintenance phases of warfarin therapy. Pharmgenomics Pers Med. 2019; 12: 1-8.

40. Al-Eitan L, Elsaqa BZ, Almasri AY, Alghamdi M. Influence of PSRC1, CELSR2, and SORT1 Gene Polymorphisms on the Variability of Warfarin Dosage and Susceptibility to Cardiovascular Disease. Pharmacogenomics and Personalized Medicine. 2020; 13: 619-632.

41. De T, Park CS, Perera MA. Cardiovascular Pharmacogenomics: Does It Matter If You're Black or White?. Annu Rev Pharmacol Toxicol. 2019;59:577-603.

42. Rafiee S, Rajabibazl M, Meshkani R, Daraei A, Zargari M, Sharafeddin F, Fazeli Z, Toffani Milani A, Taherkhani M. Association of Warfarin Therapy with APOE and VKORC1 Genes Polymorphism in Iranian Population. Iran J Pharm Res. 2017. 16(3):1230-1237.

43. Liu R, Zhang K, Gong ZZ, et al. Association of apolipoprotein E (APOE) polymorphisms with warfarin maintenance dose in a northern Han Chinese population. Lipids Health Dis. 2016;15:34.

44. Caldwell MD, Awad T, Johnson JA, et al. CYP4F2 genetic variant alters required warfarin dose. Blood. 2008; 111(8): 4106-4112.

45. Jarrar YB, Hamadneh L, Iqtait D, Sadieh R, Al-Bawab AQ, Zihlif M. The Cytochrome 4F2 rs2108622 Genetic Variant among Unrelated Arab Jordanian Volunteers. J Med J. 2017; 51 (2): 69-76.

46. Nakamura K, Obayashi K, Araki T, et al. CYP4F2 gene polymorphism as a contributor to warfarin maintenance dose in Japanese subjects. Journal of clinical pharmacy and therapeutics. 2012; 37(4): 481-485.

47. Kimmel SE, Christie J, Kealey C, et al. Apolipoprotein E genotype and warfarin dosing among Caucasians and African Americans. The pharmacogenomics journal. 2008; 8(1): 53-60.

48. Cavallari LH, Langaee TY, Momary KM, et al. Genetic and Clinical Predictors of Warfarin Dose Requirements in African Americans. Clinical Pharmacology \& Therapeutics. 2010; 87(4): 459-464.

49. Lal S, Sandanaraj E, Jada SR, et al. Influence of APOE genotypes and VKORC1 haplotypes on warfarin dose requirements in Asian patients. British journal of clinical pharmacology. 2008; 65(2): 260-264.

50. Kohnke H, Scordo MG, Pengo V, et al. Apolipoprotein E (APOE) and warfarin dosing in an Italian population. European journal of clinical pharmacology. 2005; 61(10): 781-783

51. Shahin M, Khalifa S, Gong Y, et al. Genetic and nongenetic factors associated with warfarin doserequirements in Egyptian patients. Pharmacogenetics and Genomics. 2011; 21(3): 130-135.

52. Limon-sztencel A, Lipska-zi BS, Chmara M, et al. The algorithm for Alzheimer risk assessment based on APOE promoter polymorphisms. Alzheimer's research \& therapy. 2016; 8(1): 19

53. Kalra M, Pal P, Kaushal R, et al. Association of ApoE genetic variants with obstructive sleep apnea in children. Sleep medicine. 2008; 9(3): 260-265. 
54. Ezzeldin N, El-lebedy D, Darwish A, et al. Association of genetic polymorphisms CYP2A6* 2 rs1801272 and CYP2A6* 9 rs28399433 with tobacco-induced lung Cancer: a case-control study in an Egyptian population. BMC Cancer. 2018; 18(1): 525 .

55. Freeman BD, Zehnbauer BA, Mcgrath $\mathrm{S}$, et al. Cytochrome P450 polymorphisms are associated with reduced warfarin dose. Surgery. 2000; 128(2): 281-285.

56. Tanner JA, Tyndale RF. Variation in CYP2A6 Activity and Personalized Medicine. J Pers Med. 2017;7(4):18. 